\title{
E Pluribus Unum: Macroeconomic Modelling for Multi-agent Economies*
}

\author{
Tiziana Assenza \\ Catholic University of Milan and \\ CeNDEF University of Amsterdam
}

Domenico Delli Gatti

Catholic University of Milan

\begin{abstract}
From the point of view of the average macroeconomist, agent based modelling has an obivious drawback: It makes impossible to think in aggregate terms. The modeller, in fact, can reconstruct aggregate variables only "from the bottom up" by summing the individual quantities. As a consequence the interpretation of the trasmission mechanism of shocks is somehow arbitrary. We propose a modelling strategy which reduces the dimensionality of an agent based framework by replacing the actual distributional features (in our model: the distribution of firms' financial conditions) with the first and second moments of the distribution itself. The main message is that the difficulty of thinking in macroeconomic terms when dealing with multi-agent economies can be circumvented by means of an appropriate aggregation procedure - which we label the Modified-Representative Agent - such that the distribution of agents' characteristics can be approximated by (at least) the (first and second) moments of the distribution. The moments of the distribution play the role of macroeconomic variables.
\end{abstract}

${ }^{*}$ We would like to thank for useful comments and criticisms on a preliminary version of this paper the participants to the Workshop on Economics with Heterogeneous Interacting Agents, University of Bologna,2006; Ph. D. Conference in Economics, Volterra, 2006; Computing in Economics and Finance, HEC Montreal, 2007; workshop on Artificial Economics, University of Palermo, 2007; Complex Markets workshop, University of Warwick,2008; GdR on Monetary Economix, University of Bordeaux, 2009. We have revised the structure and the exposition of the model substantially following their comments. 
We put this strategy at work in a model of the financial accelerator in which firms' heterogeneous degree of financial robustness affect investment in a bankruptcy risk context (à la Greenwald-Stiglitz).

JEL codes: E32, E43, E44, E52

Keywords: Financial Fragility, Heterogeneity, Stochastic Aggregation, Business Fluctuations. 


\section{Introduction}

It is almost a commonplace (and a trivial statement) that the Representative Agent (RA) assumption is inadequate to deal with multi-agent economies characterized by persistent and relevant heterogeneity of agents' characteristics. By persistent heterogeneity we mean the situation in which agents' differences - in the present paper we will deal with heterogeneity of financial conditions across firms - is not bound to disappear "in the long run". Heterogeneity, even if persistent, can be irrelevant if the second and higher moments of the distribution of agents' characteristics play an insignificant role in explaining the aggregate behaviour of the economy. In this case, in fact, the dynamics of the average agent captures almost all of the dynamics of the aggregate. ${ }^{1}$

If heterogeneity is both persistent and relevant, the RA assumption should be dismissed and the analysis should identify and track the law governing the evolution of the entire distribution of agents' characteristics over time. Conceptually, the starting point is the definition of heterogeneous behavioural rules at the micro level so that the aggregate (macroeconomic) quantity such as GDP - can be determined from the bottom up, i.e. by adding up the levels of a myriad of individual quantities. The increasing availability of computational power has allowed the implementation of this procedure in multi-agent models. Not surprisingly, in the last ten years or so, a proliferation of agent-based models has paralleled the diffusion of research on issues concerning heterogeneity. ${ }^{2}$

Multi-agent modelling therefore is the most straightforward way of tackling the heterogeneity issue. From the point of view of the average macroeconomist, however, it has a destructive consequence:The dimension of the model explodes. In an agent-based framework, macroeconomic thinking i.e. thinking in terms of aggregate or macro-variables - is prima facie impossible. ${ }^{3}$

\footnotetext{
${ }^{1}$ An example of persistent but irrelevant heterogeneity has been put forward by Krusell and Smith (1998), who build a model whose aggregate behaviour is explained almost entirely by the dynamics of the first moment - i.e. the mean - of the distribution. If heterogeneity is persistent but "does not matter", the modeller is entitled to ignore higher moments of the distribution and rely comfortably again on the Representative (average) agent as a reasonable approximation to reality.

${ }^{2}$ In the following we will use the expressions agent-based model or multi-agent model as synonimous. See Tesfatsion (2006) for a thorough introduction to agent based modelling.

${ }^{3}$ There are also two other majour sources of skepticism concerning agent based models:
} 
The main message of the present paper is that the difficulty of thinking in macroeconomic terms when dealing with multi-agent economies can be circumvented by means of an appropriate aggregation procedure - which we label the Modified-Representative Agent - such that the distribution of agents' characteristics can be approximated by (at least) the (first and second) moments of the distribution. The bottom line is that the moments of the distribution play the role of macroeconomic variables. In this way one can resume macroeconomic thinking in a multi-agent framework. ${ }^{4}$

As a benchmark for the application of this methodology, we build a multiagent Financial Accelerator framework of the Greenwald-Stiglitz type starting from the assumption, well corroborated by the existing evidence, that firms differ from one another according to their financial conditions, captured by the ratio of net worth to the capital stock (equity ratio). ${ }^{5}$

From simulation of the multi agent model we obtain synthetic data of the firms' equity ratio. From these data we estimate a linear dynamic system which describes the evolution over time of the mean and the variance of the distribution of the equity ratio. We nest this linear dynamic system into an otherwise standard (optimizing) IS-LM framework. In fact, the moments of the distribution of the equity ratio determine the external finance premium, which is a shifter of the IS curve. In equilibrium the interest rate and the out-

(i) the output of computer simulations does not yield clearcut and logically unobjectionable results; (ii) adaptive micro-behavioural rules are often ad hoc. Skepticism of type (i) is rapidly losing ground. First of all, the results of multi-agent models can be checked for robustness by means of a vast array of numerical tools, from Montecarlo simulations to sensitivity analysis. Calibration and validation is ranking high in the agenda of multiagent models' implementation. Second, after all most macrodynamic models - from RBC to NK DSGE models - resort to numerical methods to assess, for instance, the optimality of solutions or the relative importance of possibly contrasting effects.

As to skepticism of type (ii), it is true that multi-agent models have been extensively used to study the impact of different behavioural rules of thumb, which are often traced back to bounded rationality and adaptive behaviour. There is no reason, however, to assume that this is the only way of modelling individual choices. The multi-agent framework can also accomodate models of optimizing behaviour of heterogeneous agents. The model presented in this paper is a case in point as we will argue in a while.

${ }^{4}$ The procedure has already been used. See Agliari et al. (2000). It is thoroughly discussed and compared with other aggregation procedures in Gallegati et al. (2006) where it is labelled the Variant-Representative-Agent methodology, with a somewhat paradoxical touch.

${ }^{5}$ There is plenty of evidence, moreover, that this heterogeneity is persistent: the output of simulations of the multi-agent model will replicate this simple well established fact. 
put gap turn out to be functions of the moments of the distribution. Changes of the moments over time, therefore, impact upon the macroeconomic equilibrium. On the other hand, the equilibrium interest rate affects the law of motion of the firm's equity ratio.

In the "long run" - i.e. when the dynamical system settles in the steady state - the distribution of the equity ratio reaches a configuration which is summarized by the steady state cross sectional mean and variance. These moments determine the long run external finance premium, which in turn determines the equilibrium interest rate and output gap.

We put the model to work exploring the impact of a monetary expansion. On impact, the LM curve shifts down along the original IS curve, the interest rate goes down and the output gap goes up as expected. In our framework, however, this is not the end of the story. The reduction of the interest rate in fact activates a financial amplification mechanism due to the increase of the average equity ratio and the decrease of the variance which make the external finance premium shrink. The financial amplification effect is nicely captured by the shift up of the IS curve. The macroeconomic intuition is restored and the interpretation of the transmission mechanism clearly enhanced. The combined exploitation of the linear dynamical system obtained from the simulation and of the optimizing IS-LM framework allows to cope with heterogeneity in the simplest way at a purely macroeconomic level.

The paper is organized as follows. In section 2 we describe the behaviour of financially constrained firms. Section 3 is devoted to the application of the stochastic aggregation procedure to the investment ratio. In section 4 we analyze the behaviour of households. In section 5 we describe and discuss the IS-LM framework and determine macroeconomic equilibrium. In section 6 we describe the dynamics generated by the model and the output of simulations. Section 7 presents the derivation of the dynamical system which describes the evolution over time of the mean and the variance of the distribution of the equity ratio and determine the long run configuration of the distribution and of the long run equilibrium levels of the endogenous variables, the interest rate and the output gap. Section 9 recapitulates the modelling strategy and concludes. Technical details and cumbersome computations concerning the probability of bankruptcy, the household optimization problem and the law of motion of thye individual equity ratio are shown in the appendix. 


\section{Firms}

Firms will be indexed by $i=1,2, \ldots, z$ with $z$ "large". They produce a homogeneous good by means of capital and labor. These assumptions imply that the market structure is competitive, i.e. firms are price takers.

Financial conditions. Firms are heterogeneous with respect to their financial robustness captured by the equity ratio $a_{i t}$. In other words, the equity ratio of the i-th firm at time $\mathrm{t} a_{i t}$ is a random variable with support $(0,1)$, whose distribution is characterized by expected value $E\left(a_{i t}\right)=a_{t}$ - i.e. the average equity ratio (or cross-sectional mean of the equity ratio) and variance $E\left(a_{i t}-a_{t}\right)^{2}=V_{t}$. The representative agent is a particular case of this framework: it coincides with the average agent when the variance is zero. In other words the representative agent is the zero-variance average agent.

Firms cannot raise external finance on the equity market (due to equity rationing: Myers and Majluf, 1984; Greenwald et al., 1984) so that they have to rely on bank loans to finance investment. Therefore, they run the risk of bankruptcy. Banks extend credit to firms at an interest rate which is uniform across firms and equal to the interest rate on bonds.

Technology and market structure. Each firm carries on production by means of a constant returns to scale technology that uses labor and capital as inputs. For simplicity we assume that technology is of the Leontief type and uniform across firms. The production function of the i-th firm therefore is $Y_{i t}=\min \left(\lambda N_{i t}, \nu K_{i t}\right)$ where $Y_{i t}, N_{i t}$ and $K_{i t}$ represent output, employment and capital, $\nu$ and $\lambda$ are positive parameters which measure the productivity of capital and labour respectively.

Assuming that labour is always abundant, we can write $Y_{i t}=\nu K_{i t}$ and

$N_{i t}=\frac{\nu}{\lambda} K_{i t} . \quad \nu$ is the reciprocal of the capital/output ratio. $\frac{\nu}{\lambda}$ is the reciprocal of the capital/labour ratio. Since these parameters are constant, by assumption output, capital and employment change at the same rate. We will determine the rate of capital accumulation endogenously (see below) and will assume that output and employment change at the same rate of the capital stock.

Profit. Profit of the i-th firm in real terms in the current period $\left(\pi_{i t}\right)$ is the difference between revenues $\left(u_{i t} Y_{i t}\right)$ and total costs, which consist of 
production costs $\left(w N_{i t}+r K_{i t}\right)$ and adjustment costs $\left(\frac{1}{2} \frac{I_{i t}^{2}}{\bar{K}_{t-1}}\right)$ :

$$
\pi_{i t}=u_{i t} Y_{i t}-w N_{i t}-r_{t} K_{i t}-\frac{1}{2} \frac{I_{i t}^{2}}{\bar{K}_{t-1}}
$$

$u_{i t}$ is the average revenue of the firm. We assume that it is a random variable uniformly distributed over the interval $(0,2)$ with $E\left(u_{i t}\right)=1$ where $E\left(u_{i t}\right)$ is the expected value of the firms' average revenues, i.e. the expected average revenue. In other words, we assume that the firm faces an idiosyncratic shock to revenue due, for instance, to a sudden change in preferences. For simplicity and as a first step towards a more realistic setting we assume that the real wage $w$ is given and constant. $r_{t}$ is the real interest rate, $I_{i t}=K_{i t}-K_{i t-1}$ is investment $^{6} K_{t}=\sum_{i=1}^{z} K_{i t}$ is the aggregate capital stock and $\bar{K}_{t-1}=\frac{K_{t-1}}{z}$ is the average capital stock.

Adjustment costs are quadratic in investment (as usual in investment theory) and decreasing in the average capital stock (of the previous period). We assume a positive externality in the accumulation of capital: the higher the economywide capital stock, the lower adjustment costs for the individual firm. This is essentially a technical assumption, which allows to determine a relatively simple interior solution to the firm's optimization problem (see below).

Bankruptcy. The probability of bankruptcy for the i-th firm depends, among other things, on the equity ratio (see appendix A for a discussion). For the sake of analytical tractability we assume that firms adopt the following proxy of the probability of bankruptcy:

$$
\Phi_{i t} \approx \frac{\alpha}{a_{i t-1}}
$$

where $0<\alpha<1$. From (2.2) follows that the firm goes bankrupt with probability one if the equity ratio falls to $\alpha$. Therefore $\alpha$ represents the bankruptcy threshold, i.e. the minimum admissible equity ratio. On the other hand, since the maximum equity ratio is one, the minimum probability of bankruptcy is $\alpha$. Hence both $a_{i t-1}$ and $\Phi_{i t}$ are defined on the interval $(\alpha, 1)$ as shown in figure 2.1 .

\footnotetext{
${ }^{6}$ For the sake of simplicity we assume that there is no depreciation.
} 


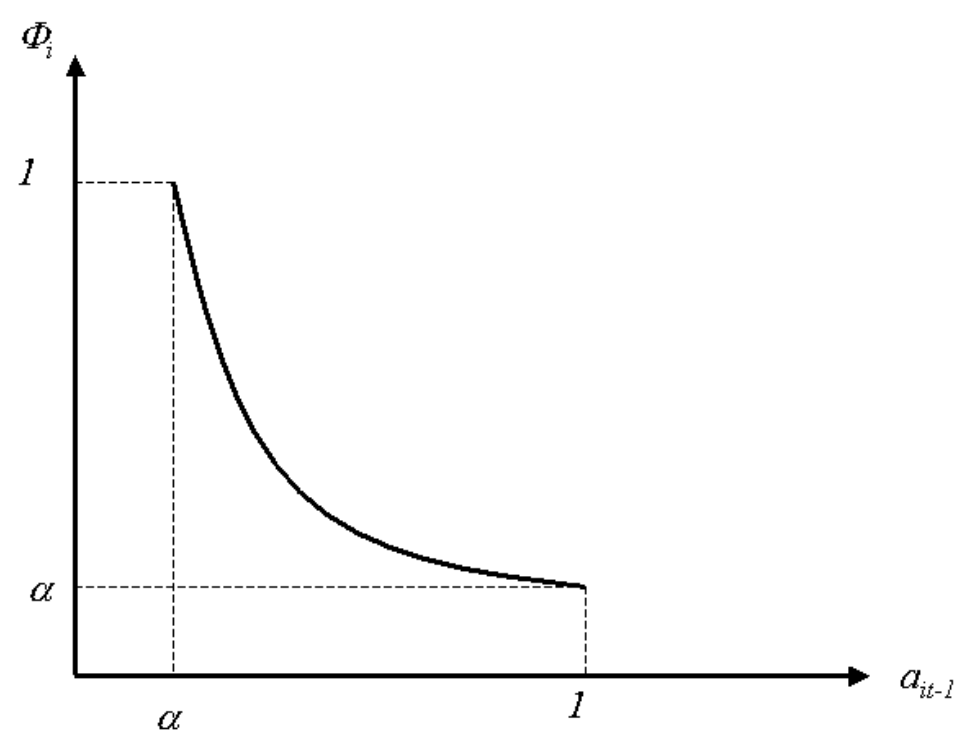

Figure 2.1: Probability of bankrupcty

Also definition (2.2) is essentially a technical assumption which allows to capture the main determinant of the probability of bankruptcy, i.e. a measure of financial robustness. More complicated formulations of the probability of bankruptcy would have made the model very difficult to manage without adding much in terms of insights. ${ }^{7}$

The convexity of the probability of bankruptcy as defined in (2.2) has an appealing property. Since $\left|\frac{d \Phi_{i t}}{d a_{i t-1}}\right|=\frac{\alpha}{a_{i t-1}^{2}}$, the stronger the financial condition of the firm - i.e. the greater the equity ratio - the lower the decrease of the probability of bankruptcy associated with a further strengthening of the financial condition, i.e. a further increase of the equity ratio. In other words the marginal probability of bankruptcy $\left|\frac{d \Phi_{i t}}{d a_{i t}-1}\right|$ is decreasing with financial robustness.

Following Greenwald and Stiglitz (1993) we assume that bankruptcy is costly and the cost of bankruptcy is an increasing linear function of the

\footnotetext{
${ }^{7}$ See appendix A for details.
} 
capital that the firm owns, i.e. $C B_{i t}=\beta K_{i t}$ where $\beta$ is a positive parameter.

The objective function of the firm is the difference between expected profit $E\left(\pi_{i t}\right)$ and bankruptcy cost in case bankruptcy occurs $C B_{i t} \Phi_{i t}$ :

$$
E\left(\pi_{i t}\right)-C B_{i t} \Phi_{i t}=Y_{i t}-w N_{i t}-r_{t} K_{i t}-\frac{1}{2} \frac{I_{i t}^{2}}{\bar{K}_{t-1}}-\beta K_{i t} \frac{\alpha}{a_{i t-1}}
$$

Since $Y_{i t}=\nu K_{i t}$ and $N_{i t}=\frac{\nu}{\lambda} K_{i t}$ the problem of the firm boils down to the following:

$$
\max _{K_{i t}}(\gamma-r) K_{i t}-\frac{1}{2} \frac{\left(K_{i t}-K_{i t-1}\right)^{2}}{\bar{K}_{t-1}}-\beta \alpha \frac{K_{i t}}{a_{i t-1}}
$$

where $\gamma \equiv \nu\left(1-\frac{w}{\lambda}\right)$ represents earnings before interest - i.e. revenue net of labour costs - per unit of capital. In the following we will refer to $\gamma$ as the profit rate.

The control variable in the problem above is the individual capital stock. Due to Leontief technology, once the stock of capital has been optimally determined, both output and employment follow being proportional to capital.

From the FOC we obtain:

$$
\tau_{i t}=\gamma-\left(r_{t}+f_{i t}\right)
$$

where $\tau_{i t} \equiv \frac{I_{i t}}{\bar{K}_{t-1}}$ is the investment ratio and

$$
f_{i t} \equiv \beta \Phi_{i t}=\frac{\beta \alpha}{a_{i t-1}}
$$

is the expected marginal bankruptcy cost.

According to (2.4) the investment ratio is the difference between the profit rate $\gamma$ and the interest rate $r_{t}$ "augmented" by a factor $\beta \Phi_{i t}=\frac{\beta \alpha}{a_{i t-1}}$, i.e. the expected marginal bankruptcy cost. When the firm has not enough internal funds and must borrow to finance investment, the cost of capital is the sum of the interest rate $r_{t}$ plus an expected extra-cost due to the risk of bankruptcy, which plays the role of the external finance premium. In the present context the external finance premium is due to the risk of insolvency as per- 
ceived by the borrower (borrower's risk) while in the framework pioneered by Bernanke and Gertler it is traced back to the the risk of default as perceived by the lender (lender's risk) (see Bernanke and Gertler, 1989, 1990; Bernanke, Gertler and Gilchrist, 1999). As in the aforementioned literature, however, also in this context the external finance premium is increasing with the probability of bankruptcy and therefore decreasing with a measure of financial soundness, namely the equity ratio. $^{8}$

As one could expect, the investment ratio is decreasing with the input $\operatorname{costs}\left(\tau_{i w}=-\frac{\nu}{\lambda}<0, \tau_{i r}=-1<0\right)$ and increasing with the equity ratio. In fact

$$
\frac{\partial \tau_{i t}}{\partial a_{i t-1}}=\frac{\beta \alpha}{a_{i t-1}^{2}}>0
$$

In the case of the representative agent, from the FOC we obtain:

$$
\tau_{t}^{R}=\gamma-\left(r_{t}+f_{t}^{R}\right)
$$

where $\tau_{t}^{R} \equiv \frac{I_{t}}{K_{t-1}}$ and $f_{t}^{R} \equiv \beta \Phi_{t}=\frac{\beta \alpha}{a_{t-1}}$ (expected average marginal bankruptcy cost).

Finally in the absence of bankruptcy $\operatorname{costs}(\beta=0)$ we obtain the first best:

$$
\tau_{t}^{F}=\gamma-r_{t}
$$

In the first best the investment ratio is equal to the profit rate after interest payment and depends only on the costs of primary inputs $w, r_{t}$. Of course, in the first best financial robustness $a_{i t-1}$ has no role to play. ${ }^{9}$

\footnotetext{
${ }^{8}$ In principle $\tau_{i t}$ can be negative. In this case the capital stock is shrinking, a situation which we could not rule out - due for instance to a process of "creative destruction" which requires the stripping of obsolete machinery. Of course the capital stock cannot be negative: therefore, in case $\tau_{i t}<0$, we impose the following restriction: $\tau_{i t}>-s_{i t-1}$ where $s_{i t-1} \equiv \frac{K_{i t-1}}{\bar{K}_{t-1}}$ is the relative size of the firm in $t-1$. The most common scenario in which capital is growing occurs if $\tau_{i t}>0$. According to $(2.4) \tau_{i t}>0$ iff $a_{i t-1}>\frac{\beta \alpha}{\gamma-r_{t}}$.

${ }^{9}$ In case there were no bankruptcy cost, i.e. $\beta=0,(2.3)$ would simplify to:

$$
E\left(\pi_{i t}\right)=Y_{i t}-w N_{i t}-r K_{i t}-\frac{1}{2} \frac{I_{i t}^{2}}{\bar{K}_{t-1}}
$$

i.e to expected profit. Financial robustness has no role to play in the maximization of
} 
Notice that, according to intuition, in the first best the investment ratio is always greater than in the presence of the risk of default: $\tau_{i t}=\tau_{t}^{F}-\frac{\beta \alpha}{a_{i t-1}}$. Moreover $\tau_{t}^{F}>\tau_{t}^{R}$.

\section{The average investment ratio}

The average investment ratio $\tau$ is the average of individual investment ratios. Hence, it depends on the entire distribution of the firms'degree of financial robustness $\left(a_{1 t-1}, a_{2 t-1}, . ., a_{z t-1}\right)$.

Using Taylor's formula and computing the derivatives at the average equity ratio we can write:

$\tau_{i t}=\tau_{t}^{R}+\frac{\partial \tau_{i t}}{\partial a_{i t-1}}\left(a_{i t-1}-a_{t-1}\right)+\frac{1}{2} \frac{\partial^{2} \tau_{i t}}{\partial a_{i t-1}^{2}}\left(a_{i t-1}-a_{t-1}\right)^{2}+\frac{1}{6} \frac{\partial^{3} \tau_{i t}}{\partial a_{i t-1}^{3}}\left(a_{i t-1}-a_{t-1}\right)^{3}+\ldots$

Taking the expected value of the expression above and recalling that, by definition, $E\left(a_{i t-1}-a_{t-1}\right)=0$ one gets:

$\tau_{t}=E\left(\tau_{i t}\right)=\tau_{t}^{R}+\frac{1}{2} \frac{\partial^{2} \tau_{i t}}{\partial a_{i t-1}^{2}} E\left(a_{i t-1}-a_{t-1}\right)^{2}+\frac{1}{6} \frac{\partial^{3} \tau_{i t}}{\partial a_{i t-1}^{3}} E\left(a_{i t-1}-a_{t-1}\right)^{3}+\ldots$

where $E\left(a_{i t-1}-a_{t-1}\right)^{2}=V_{t-1}$ and $E\left(a_{i t-1}-a_{t-1}\right)^{3}$ is the third moment around the mean, an indicator of skewness.

From the equation above follows that

The average investment ratio is equal to the investment ratio of the Representative Agent augmented by a weighted sum of all the moments of the distribution of the equity ratio. In the following, in order to keep the analysis as simple as possible, we will cut short the series above at the second term, i.e. we will approximate the average investment ratio as follows

$$
\tau_{t} \approx \tau_{t}^{R}+\frac{1}{2} \frac{\partial^{2} \tau_{i t}}{\partial a_{i t-1}^{2}} V_{t-1}
$$

where

$$
\frac{\partial^{2} \tau_{i t}}{\partial a_{i t-1}^{2}}=-\frac{2 \beta \alpha}{a_{t-1}^{3}}<0
$$

expected profits because there are no bankruptcy costs. 
Therefore equation (3.1) boils down to:

$$
\tau_{t} \approx \tau_{t}^{R}-\frac{\beta \alpha}{a_{t-1}^{3}} V_{t-1}=\gamma-\left(r_{t}+f_{t}\right)
$$

where

$$
f_{t} \equiv \frac{\beta \alpha}{a_{t-1}}\left(1+\frac{V_{t-1}}{a_{t-1}^{2}}\right)=f\left(a_{t-1}, V_{t-1}\right), \quad f_{a_{t-1}}<0, \quad f_{V_{t-1}}>0 .
$$

is the average external finance premium.

According to (3.2)

Proposition 1 The average investment ratio is equal to the investment ratio of the representative agent corrected by a factor which depends on the cross-sectional variance of the equity ratio. In this sense, we are now in a macroeconomic context characterized by a Modified-Representative Agent. It turns out that the investment ratio of the modified representative agent is the difference between the profit rate $\gamma$ and the interest rate $r_{t}$ "augmented" by the average external finance premium which is decreasing with the average equity ratio and increasing with the variance of the equity ratio. ${ }^{10}$

Notice that the average investment ratio in the presence of heterogeneity $\tau$ is smaller than the investment ratio of the representative agent $\tau_{t}^{R}$ which in turn is smaller than the first best investment ratio $\tau_{t}^{F}$. In other words we have the following hierarchy of investment ratios

$$
\tau_{t}^{F}>\tau_{t}^{R}>\tau_{t}
$$

To illustrate this point, in figure 3.1 we represent equation (2.4). The investment ratio of the i-th firm $\tau_{i t}$ is an increasing concave function of the individual equity ratio $a_{i t-1}$ and tends asymptotically to the first best $\tau_{t}^{F}$. Concavity of the investment ratio can be traced back to convexity of the bankruptcy probability function (2.2). In fact $\frac{\partial \tau_{i t}}{\partial a_{i t-1}}=\beta\left|\frac{d \Phi_{i t}}{d a_{i t-1}}\right|$ : the

\footnotetext{
${ }^{10}$ In other words, the external finance premium $f_{t}$ can be conceived of as a mark-up $\mu_{t-1}:=\frac{V_{t-1}}{a_{t-1}^{2}}$ on the external finance premium in the representative agent case $f_{t}^{R}:=\frac{\beta \alpha}{a_{t-1}}$ where the mark-up coincides with the square of the "coefficient of variation" i.e. the ratio of the standard deviation to the mean of the distribution.
} 


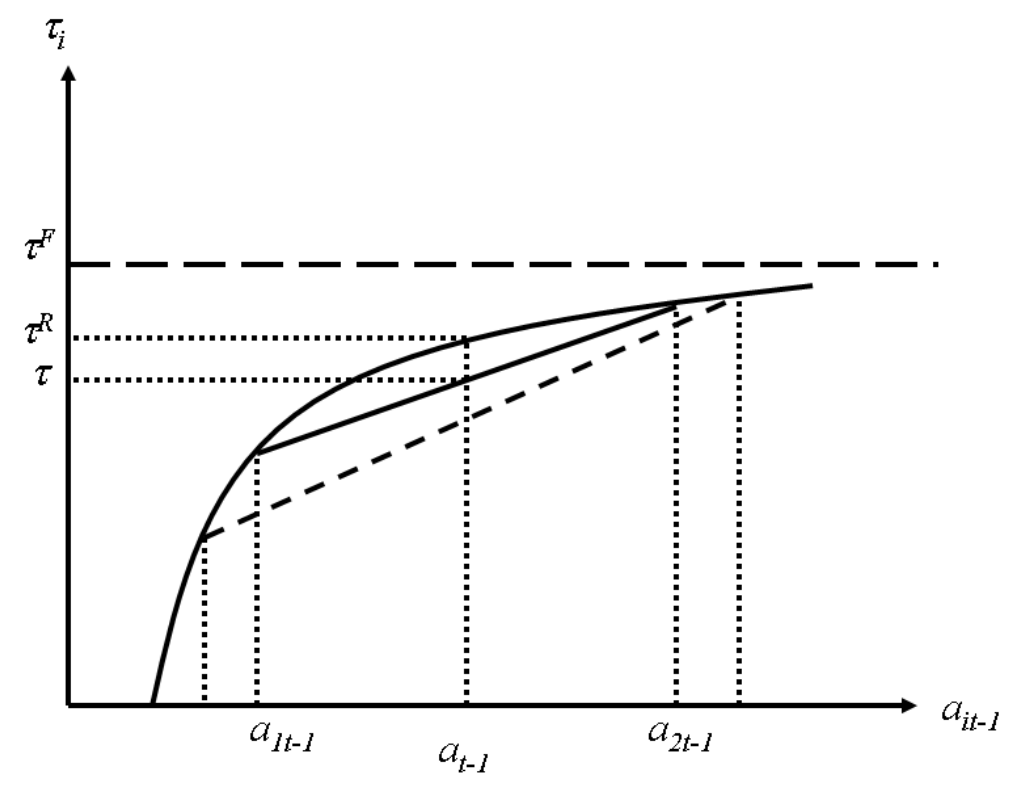

Figure 3.1: Individual investment ratio

stronger the financial condition of the firm - i.e. the greater the equity ratio - the smaller the reduction of the probability of bankruptcy associated with an increase of the equity ratio, and therefore the smaller the increase of the investment ratio.

For the sake of discussion, consider the simplest case of a corporate sector consisting of just two firms, indexed 1 and 2 , whose equity ratios are $a_{1 t-1}$ and $a_{2 t-1}$. Thanks to concavity of the investment ratio, by Jensen's inequality, the average investment ratio $\tau_{t}$ will be smaller than the investment ratio associated with the average equity ratio $\tau_{R}$-i.e. the investment ratio of the representative agent - which in turn will be smaller than first best. A mean preserving increase in dispersion will bring about a decrease of the average investment ratio.

Average investment will be $\bar{I}_{t}=\tau_{t} \bar{K}_{t-1}$ so that in the aggregate $I_{t}=$ $\tau_{t} K_{t-1}$ and therefore $K_{t}=\left(1+\tau_{t}\right) K_{t-1}$. Therefore the average investment ratio represents also the rate of growth of the aggregate capital stock: $\tau_{t}=g_{t}$. 
Due to the Leontief technology also employment and output grow at the same rate as the capital stock.

\section{Households}

For the sake of simplicity, we assume that households are homogeneous in every respect so that we can adopt the representative agent hypothesis. Households demand consumption goods, financial assets (bonds) and money balances. Money balances provide "liquidity services" which are necessary if transactions require a means of payment, as we will assume.

The representative household has a measure 1 of members. The household supplies inelastically one unit of labour. In period t each member of the household may be employed with probability $x_{t}$ or unemployed with probability $1-x_{t}$. Assuming that the law of large numbers applies, $x_{t}$ coincides with the fraction of household's members who are employed. Since we adopt the representative agent approach (as far as households are concerned), $x_{t}$ can be thought of also as the employment rate economywide. Therefore $1-x_{t}$ is the unemployment rate.

Since by assumption all the profits are retained within the firm, the only source of income for the household's member is the wage rate $w$ if she employed, the unemployment subsidy $\sigma$ if unemployed, with $w>\sigma$. The expected household's income therefore is $w x_{t}+\sigma\left(1-x_{t}\right)$. For simplicity, both the real wage and the unemployment subsidy are assumed to be constant. As to the probability of being employed, we assume that in each period it is known to the household. Notice however that this is not an exogenous variable. We will determine the employment rate in general equilibrium in the following section. In the following, in order to avoid unnecessary complications at this stage of the analysis, we will keep the aggregate price level constant and normalize it to unity.

The lifetime utility function of the representative household is:

$$
U_{t}=\sum_{s=0}^{\infty}\left(\frac{1}{1+\rho}\right)^{s}\left(c_{t+s}\right)^{\delta}\left(m_{t+s}\right)^{1-\delta}
$$

where $c_{t}$ is consumption, $m_{t}$ are (per capita) money balances, $\rho$ is the rate of time preference, $0<\delta<1$. In the following, for simplicity, we will set $\delta=1 / 2$ 
The household's budget constraint is:

$$
c_{t}+m_{t}+b_{t}=w x_{t}+\sigma\left(1-x_{t}\right)+m_{t-1}+\left(1+r_{t}\right) b_{t-1}
$$

where $b_{t}$ are bonds (per capita) and $r_{t}$ is the interest rate on bonds.

According to the budget constraint, the sum of consumption and the demand for money and bonds should be equal to income plus interest payments $\left(1+r_{t}\right) b_{t-1}$ and money balances $m_{t-1}$ (carried over from the previous period).

The problem of the representative household, therefore, consists in maximizing the expected value of (4.1) subject to (4.2). From the FOCs ${ }^{11}$ we obtain the following relation between optimal consumption and money demand:

$$
m_{t}=\frac{1+r_{t}}{r_{t}} c_{t}
$$

We assume that changes in money supply are implemented by means of open market operations. Therefore:

$$
m_{t}-m_{t-1}=-\left[b_{t}-\left(1+r_{t}\right) b_{t-1}\right]
$$

Substituting (4.3) and (4.4) into (4.2) we obtain the optimal consumption function and money demand function for the representative household:

$$
\begin{aligned}
c_{t} & =w x_{t}+\sigma\left(1-x_{t}\right) \\
m_{t} & =\frac{1+r_{t}}{r_{t}}\left[w x_{t}+\sigma\left(1-x_{t}\right)\right]
\end{aligned}
$$

Total consumption is the product of per capita consumption times the number of households, say $L_{t}$. Therefore:

$$
C_{t}=\left[w x_{t}+\sigma\left(1-x_{t}\right)\right] L_{t}
$$

Total demand for money is the product of per capita demand for money times the number of households. Therefore:

$$
M_{t}=\frac{1+r_{t}}{r_{t}}\left[w x_{t}+\sigma\left(1-x_{t}\right)\right] L_{t}
$$

\footnotetext{
${ }^{11}$ See appendix B for details.
} 


\section{Equilibrium}

In this economy there will be markets for labor, goods, money and bonds. Due to real wage rigidity, the labor market can be characterized by underemployment even if both the money and goods markets are in equilibrium. Thanks to Walras' law, there will be also equilibrium on the market for bonds.

The goods market is in equilibrium (planned expenditure is equal to actual expenditure) if $C_{t}+I_{t}=Y_{t}$ where $C_{t}$ is aggregate consumption defined as in (4.5), $I_{t}$ is aggregate investment: $I_{t}=\tau_{t} K_{t-1}$.

Therefore, in equilibrium the following must hold true:

$$
\left[w x_{t}+\sigma\left(1-x_{t}\right)\right] L_{t}+\tau_{t} K_{t-1}=Y_{t}
$$

Dividing by $N_{t}$, and recalling that $\frac{N_{t}}{L_{t}}=x_{t}, \frac{Y_{t}}{N_{t}}=\lambda, \tau_{t} \frac{K_{t-1}}{N_{t}}=\tau_{t} \frac{K_{t-1}}{K_{t}} \frac{K_{t}}{N_{t}}=$ $\frac{\tau_{t}}{1+\tau_{t}} \frac{\lambda}{\nu}$ we can rewrite (5.1) as follows:

$$
w+\sigma\left(\frac{1}{x_{t}}-1\right)+\frac{\tau_{t}}{1+\tau_{t}} \frac{\lambda}{\nu}=\lambda
$$

Thanks to the linearity of technology, $x_{t}$ can be thought of also as a measure of capacity utilization. In fact, $N_{t}=Y_{t} / \lambda$ and $L_{t}=\hat{Y}_{t} / \lambda$ where $\hat{Y}_{t}$ is potential output so that $x_{t}=Y_{t} / \hat{Y}_{t}$. In the following we wll refer to $x$ as the output gap. ${ }^{12}$

In order to simplify matters, we linearize the term $\frac{1}{x_{t}}$ around full capacity (i.e. $x_{t}=1$ ) by means of the usual Taylor's procedure: $\frac{1}{x_{t}} \approx 2-x_{t}$. Therefore $\frac{1}{x_{t}}-1 \approx 1-x_{t}$. Analogously, linearizing the term $\frac{\tau_{t}}{1+\tau_{t}}$ around $\tau_{t}=0$ we get $\frac{\tau_{t}}{1+\tau_{t}} \approx \tau_{t}$. Hence 5.2 becomes $w+\sigma\left(1-x_{t}\right)+\tau_{t} \frac{\lambda}{\nu}=\lambda$. Recalling that

\footnotetext{
${ }^{12}$ Properly speaking, the output gap is an affine transformation of capacity utilization. In fact $\frac{Y-\hat{Y}}{\hat{Y}}=x-1$.
} 
$\tau_{t}=\gamma-r_{t}-f_{t}$ (see equation (3.2)) in the end we can write:

$$
w+\sigma\left(1-x_{t}\right)+\left(\gamma-r_{t}-f_{t}\right) \frac{\lambda}{\nu}=\lambda
$$

Notice that $\lambda=w+\gamma \frac{\lambda}{\nu}$. In fact $\gamma \frac{\lambda}{\nu}$ represents profits per worker, being the product of the profit rate $\gamma \equiv \nu\left(1-\frac{w}{\lambda}\right)$ times the capital/labour ratio $\frac{\lambda}{\nu}$. By definition, the sum of labour income per worker - i.e. the wage rate and non-labour income per worker is equal to income per worker.

Hence equation (5.2) becomes:

$$
x_{t}=1-\frac{\lambda}{\sigma \nu}\left(r_{t}+f_{t}\right)
$$

This relation between $r_{t}$ and $x_{t}$ represents the (optimizing) IS curve of our model.

We now turn to the money market. Total demand for money is represented by equation (4.6). Imposing the equilibrium condition $M_{t}=\bar{M}_{t}$ where $\bar{M}_{t}$ is exogeneous money supply and dividing by $L_{t}$, we get $x_{t}=$ $\frac{1}{w-\sigma}\left(\frac{r_{t}}{1+r_{t}} \bar{m}_{t}-\sigma\right)$ where $\bar{m}_{t}=\frac{\bar{M}_{t}}{L_{t}}$ represents per-capita money supply. In the following we will assume that the rate of growth of money supply will be equal to the rate of growth of population so that per capita money supply will be constant over time. Linearizing the term $\frac{r_{t}}{1+r_{t}}$ around $r_{t}=0$ we get $\frac{r_{t}}{1+r_{t}} \approx r_{t}$ so that the equation above becomes:

$$
x_{t}=\frac{1}{w-\sigma}\left(r_{t} \bar{m}-\sigma\right)
$$

This relation between $r_{t}$ and $x_{t}$ represents the LM curve of our model.

The system (??)(5.4) can be solved for the equilibrium interest rate and capacity utilization. After some algebra we get the following reduced form

$$
r_{t}=\Gamma_{0}\left[\sigma \frac{\nu}{\lambda} w-(w-\sigma) f_{t}\right]
$$




$$
x_{t}=\frac{\bar{m}}{w-\sigma} \Gamma_{0}\left[\sigma \frac{\nu}{\lambda} w-(w-\sigma) f_{t}\right]-\frac{\sigma}{w-\sigma}
$$

where

$$
\Gamma_{0}=\left(w-\sigma+\sigma \frac{\nu}{\lambda} \bar{m}\right)^{-1}
$$

is positive (since $w>\sigma$ ) and decreasing with per capita money supply. We assume

$$
\sigma \frac{\nu}{\lambda} w-(w-\sigma) f_{t}>\frac{\sigma}{\Gamma_{0} \bar{m}}
$$

in order to guarantee that both $r_{t}$ and $x_{t}$ are positive.

Since $f_{t} \equiv \frac{\beta \alpha}{a_{t-1}}\left(1+\frac{V_{t-1}}{a_{t-1}^{2}}\right)$ (see $(3.3)$ ), the moments of the distribution of the equity ratio are shifters of the IS curve. A reduction of the external finance premium (due for instance to an increase of the mean or a reduction of the variance of the equity ratio) makes the IS curve shift up so that both employment and the interest rate in equilibrium go up (compare points $E_{0}$ and $R$ in figure 7.3).

Notice that the interest rate augmented by the external finance premium is:

$$
r_{t}+f_{t}=\Gamma_{0} \sigma \frac{\nu}{\lambda} w+\left[1-\Gamma_{0}(w-\sigma)\right] f_{t}
$$

Since the expression in brackets is positive, it turns out that the augmented interest rate is increasing in $f_{t}$. Hence a reduction of the external finance premium makes the interest rate increase but the augmented interest rate decrease (because the reduction of the external finance premium is greater in absolute value than the increase of the interest rate).

Recalling that $\tau_{t}=\gamma-\left(r_{t}+f_{t}\right)$ we can conclude that a reduction of the external finance premium unambiguously boosts capital accumulation in equilibrium.

\section{Simulations}

In this section we explore the dynamics stemming from the macroeconomic model presented in the previous section by means of simulation. First of all we have to establish the law of motion of the firms' net worth. Assuming that there are no dividends, the level of net worth in real terms for the i-th firm in $t$ is defined as $A_{i t}=A_{i t-1}+\pi_{i t}$. Recalling (2.1) and proceeding as 
described in appendix $\mathrm{C}$ we obtain:

$$
a_{i t}=a_{i t-1}\left(\frac{s_{i t-1}}{s_{i t-1}+\tau_{i t}}\right)+u_{i} \nu-w \frac{\nu}{\lambda}-r_{t}-\frac{1}{2} \frac{\tau_{i t}^{2}}{s_{i t-1}+\tau_{i t}}
$$

where $\tau_{i t}=\gamma-\left(r_{t}+\frac{\beta \alpha}{a_{i t-1}}\right) ; s_{i t-1}=\frac{K_{i t-1}}{\bar{K}_{t-1}}$. Equation (6.1) is the law of motion of the individual equity ratio, which plays the most important role in the dynamics of the model. In each period, given the real wage and technological parameters, the equity ratio of the i-th firm is a function of two pre-determined individual variables, i.e. the investment ratio - which is determined by the financial robustness of the past - and the relative size, a stochastic disturbance $\left(u_{i t}\right)$ and the interest rate $r_{t}$ which is defined as in (5.5). The cross-sectional mean and variance of the equity ratio impact upon the individual law of motion through the external finance premium $f_{t}=\frac{\beta \alpha}{a_{t-1}}\left(1+\frac{V_{t-1}}{a_{t-1}^{2}}\right)$ which is incorporated into the interest rate. This is the source of a macroeconomic externality: The macroeconomic variables which summarize the shape of the distribution of the firms' financial conditions in t-1,i.e. $a_{t-1}, V_{t-1}$ affect the interest rate in $\mathrm{t}$ and through it they influence the individual financial condition in $t$.

In a multi-agent setting, the dynamics of the model are described by a myriad of laws of motion of the individual equity ratios, i.e. a multidimensional system of non-linear difference stochastic equations. Since it is impossible to compute closed form solutions for such a system, we have to resort to computer simulations to analyze the evolution of micro state variables and macrovariables.

We consider a virtual economy consisting of $z=1000$ firms, over a time span of $T=1000$ periods ("quarters"). There are 7 free parameters in the model, which are set as follows: 


\begin{tabular}{|l|l|}
\hline \multicolumn{2}{|c|}{ Table 1: Parameter setting } \\
\hline Bankruptcy threshold & $\alpha=0.02$ \\
\hline Bankruptcy cost per unit of capital & $\beta=0.002$ \\
\hline Average productivity of capital & $\nu=1 / 3$ \\
\hline Average productivity of labour & $\lambda=1$ \\
\hline Wage rate & $w=0.7$ \\
\hline Unemployment subsidy & $\sigma=0.2$ \\
\hline Money supply & $\bar{m}=200$ \\
\hline
\end{tabular}

We aim at assessing qualitatively the dynamic properties of the economy under scrutiny. Therefore we built the model as sparingly as possible, abstracting from features which would certainly enrich the model but would also increase the difficulty of understanding the mechanisms at work. For the same reason, we do not perform any calibration exercise, properly speaking. However, the configuration of parameters we have chosen will yield dynamic patterns of the main macroeconomic variables - i.e. the interest rate and the output gap - roughly in line with the empirical evidence.

As shown in section 2, for modelling reasons the threshold level of the equity ratio $\alpha$ below which the firm goes bankrupt cannot be exactly zero. The bankruptcy threshold we have chosen, however, $\alpha=0.02$, is low enough to be very close to zero.

The productivity of capital $\nu$ is set to $1 / 3$ to capture the stylized fact according to which the capital/output ratio is close to 3 in real advanced economies.

We do not have strong priors concerning the other parameters. The real wage and the productivity of labour $\lambda$ are set so that, together with the productivity of capital, they yield a profit rate (before interest) $\gamma$ equal to $10 \%$. In order to capture the most common institutional setting, the unemployment subsidy is substantially lower (less than 30\%) than the wage rate. The bankruptcy cost too is very small, amounting to $0.2 \%$ of the individual capital stock in case bankruptcy occurs.

At the beginning of the time horizon considered, i.e. in quarter $t=1$, the initial conditions are chosen as follows:

- the equity ratio $a_{i 1}$ of the i-th firm, $i=1, \ldots 1000$, is drawn from a uniform distribution over the $(0,1)$ support. Therefore the cross-sectional 
mean and variance of the initial equity ratios can be computed as $a_{1}=$ mean $\left(a_{i 1}\right) ; V_{1}=\operatorname{variance}\left(a_{i 1}\right)$;

$$
{ }_{(i)}(i)
$$

- the initial capital stock $K_{i 1}$ is drawn from a uniform distribution. Therefore, the initial relative size can be computed as $s_{i 1}=K_{i 1} / K_{1}$ where $K_{1}=\operatorname{mean}\left(K_{i 1}\right)$;

From $t=2$ on:

- the external finance premium can be computed as $f_{2}=\frac{\beta \alpha}{a_{1}}\left(1+\frac{V_{1}}{a_{1}^{2}}\right)$.

- the interest rate can be computed from (5.5). For example in $t=2$ we have

$$
r_{2}=\Gamma_{0}\left[\sigma \frac{\nu}{\lambda} w-(w-\sigma) f_{2}\right]
$$

where $\Gamma_{0}=\left(w-\sigma+\sigma \frac{\nu}{\lambda} \bar{m}\right)^{-1}$ and the parameters are set as in table 1.

- the output gap can be computed from (5.6). For example in $t=2$ we have

$$
x_{2}=\Gamma_{0} \frac{\bar{m}}{w-\sigma}\left[\sigma \frac{\nu}{\lambda} w-(w-\sigma) f_{2}\right]-\frac{\sigma}{w-\sigma}
$$

- the individual investment ratio can be computed from (2.4). For example in $t=2$

$$
\tau_{i 2}=\gamma-\left(r_{2}+\frac{\beta \alpha}{a_{i 1}}\right)
$$

Averaging we get the mean investment ratio in period $2 \tau_{2}=\underset{(i)}{\operatorname{mean}} \tau_{i 2}=$ $\gamma-r_{2}+\beta \alpha \underset{(i)}{\operatorname{mean}}\left(\frac{1}{a_{i 1}}\right)$.

- plugging these data into (6.1) we can track the evolution over time, of the individual equity ratio. For instance, in period 2 we get:

$$
a_{i 2}=a_{i 1}\left(\frac{s_{i 1}}{s_{i 1}+\tau_{i 2}}\right)+u_{i 2} \nu-w \frac{\nu}{\lambda}-r_{2}-\frac{1}{2} \frac{\tau_{i 2}^{2}}{s_{i 1}+\tau_{i 2}}
$$


where $s_{i 1}, \tau_{i 2}, r_{2}$ have already been determined as above and $u_{i 2}$ is an idiosyncratic shock drawn from a uniform distribution over the $(0,2)$ support;

- the individual capital stock can be determined according to the following law: $K_{i t}=K_{i t-1}+\tau_{i t} K_{t-1}$ where $K_{t-1}=\operatorname{mean}\left(K_{i t-1}\right)$ because, by definition, $I_{i t}=\tau_{i t} K_{t-1}$. For instance

$$
K_{i 2}=K_{i 1}+\tau_{i 2} K_{1}
$$

so that the relative size will be $s_{i 2}=K_{i 2} / K_{2}$.

- the cross-sectional mean and variance of the equity ratios can be computed - for instance $a_{2}=$ mean $\left(a_{i 2}\right) ; V_{2}=\operatorname{variance}\left(a_{i 2}\right)$ - and the sequence can be iterated.

The i-th firm goes bankrupt and exits if the equity ratio hits the bankruptcy threshold. In this case, the exiting firm is replaced by a new firm whose equity ratio is drawn from a uniform distribution over the $(0,1)$ support.

The bankruptcy threshold can be considered a "floor" for the range of admissible equity ratios that the i-th firm can experience. Symmetrically we can imagine a "ceiling" represented by an equity ratio equal to unity. If the equity ratio goes beyond unity, the firm is completely self-financed, so that it does not need to resort to bank loans to carry on production and therefore does not run the risk of bankruptcy. To keep the analysis as simple as possible, we will imagine that when the equity ratio hits the ceiling, the firm will be restarted with an equity ratio drawn from a uniform distribution over the $(0,1)$ support.

In a sense, therefore, the i-th firm is a dynasty: every time the firm goes bankrupt or becomes completely self-financed, the firm will be restarted with a new stochastic equity ratio. This device allows to keep the equity ratio within the admissible $(\alpha, 1)$ range. 


\section{Macroeconomic dynamics}

\subsection{The laws of motion of the cross sectional mean and variance}

In an agent-based setting, the dynamics of the model are described by a myriad of laws of motion of the individual equity ratios - each one represented by an equations of the form (6.1) - i.e. by a system of first order nonlinear stochastic difference equations. Since it is impossible to compute closed form solutions for such a system, we have to find a linear counterpart of the system by statistical means from the synthetic data generated through the simulations described in the previous section. These simulations, in fact, generate the time series of the cross-sectional mean and variance over 1000 periods. Running an OLS regression on 900 simulated data (we discard the transient consisting of the first 100 periods) we estimate the coefficients of the linear system

$$
\begin{aligned}
a_{t} & =\alpha_{10}+\alpha_{11} a_{t-1}+\alpha_{12} V_{t-1} \\
V_{t} & =\alpha_{20}+\alpha_{21} a_{t-1}+\alpha_{22} V_{t-1}
\end{aligned}
$$

We run several simulations changing the random seed. The estimated alfa coefficients in one of these simulations ${ }^{13}$ are

$$
\begin{aligned}
& \alpha_{10}=0.31907 ; \alpha_{11}=0.48284 ; \alpha_{12}=-0.35054 \\
& \alpha_{20}=0.05863 ; \alpha_{21}=0.02141 ; \alpha_{22}=0.24154
\end{aligned}
$$

They are all statistically significant.

In order to provide a macroeconomic interpretation of the system (7.1)(7.2), it is convenient to consider the continuous time approximation:

$$
\begin{aligned}
d a & =\alpha_{10}+\left(\alpha_{11}-1\right) a+\alpha_{12} V \\
d V & =\alpha_{20}+\alpha_{21} a+\left(\alpha_{22}-1\right) V
\end{aligned}
$$

In figure (7.1) we represent the demarcation curves $A A$ and $V V$. Imposing $d a=0$ we determine the $A A$ line, i.e the locus of $(a, V)$ pairs such that $a$ is constant. It is easy to see that the line is downward sloping. Points above (below) the line are characterized by a tendency of $a$ to decrease (increase)

\footnotetext{
${ }^{13}$ The other simulations yeld similar estimated coefficients.
} 
(as shown by the horizontal arrows).

Setting $\alpha_{12}=0$ in 7.1 we get $a_{t}=\alpha_{10}+\alpha_{11} a_{t-1}$ with $\alpha_{10}=0.31907 ; \alpha_{11}=$ 0.48284 . This is the law of motion of the equity ratio of the representative agent. The steady state of this $\mathrm{AR}(1)$ process is

$$
a_{0}^{R}=0.61696
$$

This is the the steady state equity ratio of the representative agent captured by point $R \equiv\left(a_{0}^{R}, 0\right)$ in the figure. The steady state is stable. If, for instance,

the initial condition of the equity ratio of the representative agent is $a<a_{0}^{R}$ (any point of the $\mathrm{x}$-axis between the origin and point $\mathrm{R}$ are characterized by this inequality), then $a$ will increase and converge to $a_{0}^{R}$.

Imposing $d V=0$ we determine the $V V$ line, i.e the locus of $(a, V)$ pairs such that $V$ is constant. It is easy to see that the line is upward sloping. Points above (below) the line are characterized by a tendency of $V$ to decrease (increase) (as shown by the vertical arrows).

The steady state is at the intersection of the two curves (point $E_{0}$ ). From the estimated linear system we get the coordinates of this point, namely:

$$
a_{0}=0.55517 ; V_{0}=0.092973
$$

It is easy to ascertain (by computing the eigenvalues of the system) that the steady state is stable.

We have somehow "deformed" the original non-linear model (see appendix to extract from the simulated data an ergodic process such that the actual distribution of the equity ratio converges over time to a long run stable distribution whose first and second moments are $a_{0}$ and $V_{0}$.

Notice that $a_{0}<a_{0}^{R}$. Heterogeneity (captured by the cross sectional variance) plays the role of a dampening factor with respect to the accumulation of net worth.

Not surprisingly the steady state of the cross sectional mean (and of the variance) almost coincide with the long run average of the same variables which can be computed directly from simulated data, as shown in the upper panels of figure 7.2 .

\subsection{The macroeconomic equilibrium in the steady state}

We are now able to compute the external finance premium in the "long run" i.e when the distribution of the equity ratio has reached her long run shape 


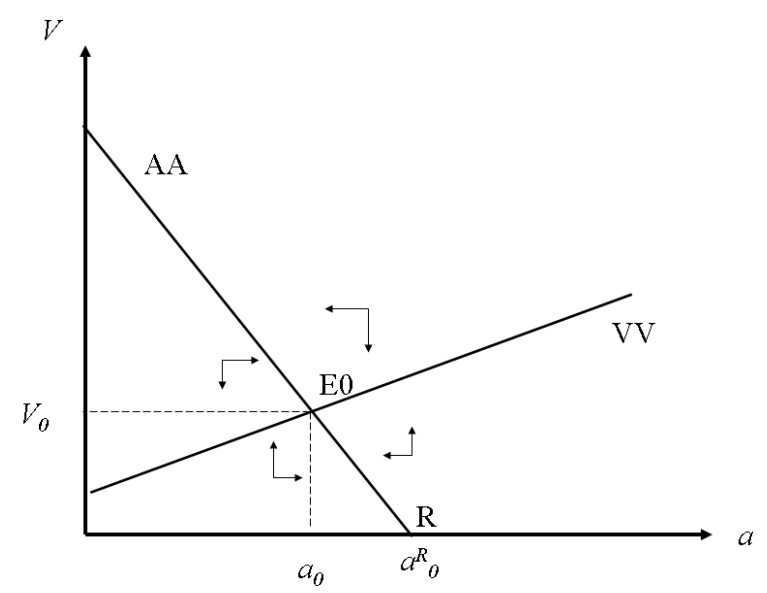

Figure 7.1: Phase diagram of (7.1)(7.2)
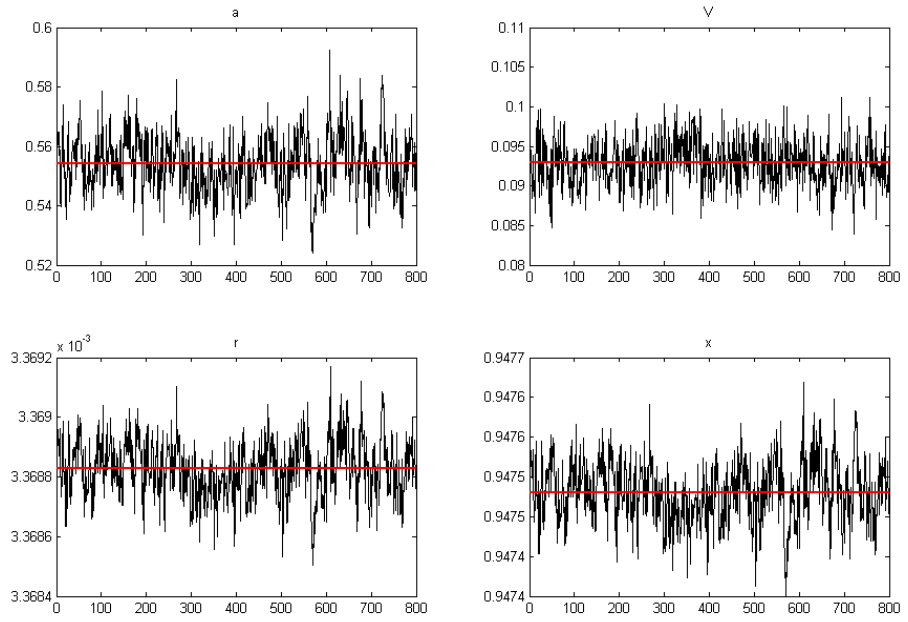

Figure 7.2: Time series of a,V,r,x. 
captured by the steady state cross sectional mean and variance:

$$
f_{0} \equiv \frac{\beta \alpha}{a_{0}}\left(1+\frac{V_{0}}{a_{0}^{2}}\right)=0.000093784
$$

This is the crucial datum we have to retrieve from simulations and plug into the reduced form $(5.5)(5.6)$ of the IS-LM model in order to compute the real interest rate and the output gap in equilibrium and in the long run. They are:

$$
\begin{aligned}
& x_{0}=0.94804 \\
& r_{0}=0.003370
\end{aligned}
$$

Therefore, in the long run the unemployment rate is approximately $5 \%$ while the annualized interest rate is around 1\%. ${ }^{14}$ Notice that the equilibrium values of the output gap and the interest rate computed above are quite close to the long run average of the same variables which can be computed directly from simulated data, as shown in the lower panels of figure 7.2.

In figure 7.3 , the equilibrium values of the interest rate and the output gap $\left(x_{0}, r_{0}\right)$ are the coordinates of the macroeconomic equilibrium $E_{0}$. By construction, the macroeconomic equilibrium is anchored to $f_{0}$.

We can easily retrieve the output gap and interest rate in the representative agent case. The external finance premium in this case, in fact, is:

$$
f_{0}^{R} \equiv \frac{\beta \alpha}{a_{0}^{R}}=0.000064834
$$

Notice that the external finance premium is lower in the representative agent case. Hence:

$$
\begin{aligned}
x_{0}^{R} & =0.94844 \\
r_{0}^{R} & =0.003371
\end{aligned}
$$

It turns out that both the interest rate and the output gap are higher in the

\footnotetext{
${ }^{14}$ These numbers are just satisfactory for our purposes. They are not too far from the macroeconomic scenario in the USA before the crisis. In this paper, however, we are not looking for an accurate reproduction of macroeconomic reality. Our aim consists in illustrating a strategy to build a fairly reasonable microfounded macroeconomic model with heterogenous agents.
} 


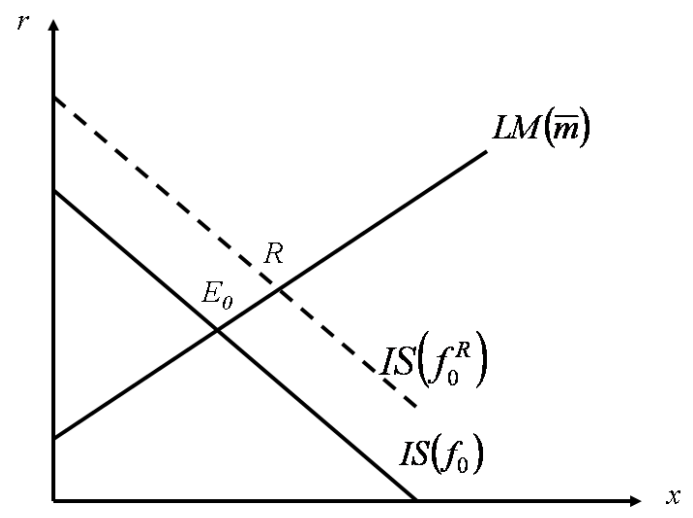

Figure 7.3: The macroeconomic equilibrium

representative agent case (see point $\mathrm{R}$ in the figure). ${ }^{15}$

Notice that $a_{0}<a_{0}^{R}$. Heterogeneity (captured by the cross sectional variance) plays the role of a dampening factor with respect to the accumulation of net worth. Where does this dampening role comes from? This is not an easy question. Our tentative answer is based upon an heuristic argument which goes as follows.

Suppose the initial cross sectional mean is $a_{-1}<a_{0}<a_{0}^{R}$. One can visualize the macroeconomic equilibrium as the intersection of the LM curve with an IS curve characterized by $f_{-1}>f_{0}^{R}$. Let's consider the RA case first. The equity ratio increases (the system moves along the $\mathrm{x}$-axis in figure 7.1). Hence, the external finance premium goes down, boosting net worth and capital accumulation. In our IS-LM framework the IS curve shifts up along the LM curve so that both the output gap and the interest rate go up. The increase of the interest rate, however, is accompanied by a reduction of the "augmented" interest rate, i.e. the interest rate augmented by the external finance premium. With the passing of time the system will settle in

\footnotetext{
${ }^{15}$ In oder not to mess up the graphical representation we do not show the first best case, which is characterized by $\tau_{t}^{F}=\gamma-r_{t}$. The first best would be captured by an IS schedule characterized by $f=0$. This schedule would be time invariant and located above the IS schedule in the representative agent case.
} 
the steady state and macroeconomic equilibrium points characterized by the letter $R$.

Let's consider now the Heterogeneous Agents (HAs) case. The same line of reasoning applies also to the cross-sectional mean of the equity ratio in the HAs case. In this latter scenario, however, the change in the variance of the equity ratio plays a crucial role. The variance goes up during the expansion, i.e. the correlation between the mean and the variance of the equity ratio is positive. In this case the reduction of the external finance premium due to the increase of the cross-sectional mean is somehow offset by the increase of the variance. Hence net worth and capital accumulation are somehow attenuated. In the end (i.e. in the steady state) the cross sectional equity ratio go up less than in the RA case.

\section{The effects of a monetary policy shock}

We now test the model to assess the effects of a monetary shock. In our setting, we simply assume that money supply increases from $m_{0}=200$ to $m_{1}=300$. We generate a new synthetic set of individual data running simulations as before but increasing the parameter $m$ from 200 to 300, the other parameters of table 1 being equal. We estimate the coefficients of the linear system (7.1)(7.2) on this new artificial dataset and get the following numerical results:

$$
\begin{aligned}
& \alpha_{10}=0.32304 ; \alpha_{11}=0.48168 ; \alpha_{12}=-0.37437 \\
& \alpha_{20}=0.05909 ; \alpha_{21}=0.019093 ; \alpha_{22}=0.24840
\end{aligned}
$$

In the new situation it is easy to see that the AA line shifts down while the VV curve shifts up. Both lines become flatter. In the proximity of the steady state the situation is as depicted in figure (8) which magnifies a relatively small portion of the $(a, V)$ plane. Thick (thin) lines characterizes the situation with $m_{1}=300\left(m_{0}=200\right)$.

Notice that in the portion of plane considered the AA curve after the monetary expansion - the new AA curve hereafter - is well above the corresponding AA curve before the expansion (the old AA curve). ${ }^{16}$ On the other

\footnotetext{
${ }^{16}$ This is due to the fact that the new (thick) AA curve, whose intercept is smaller than the intercept of the old (thin) AA curve but which is also flatter, intersects the old AA
} 


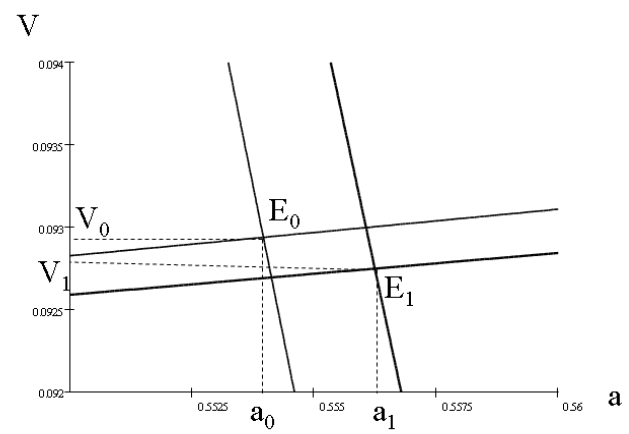

hand, the new VV curve is (slightly) below the old VV curve. ${ }^{17}$.

The steady state is at the intersection of the two curves (point $E_{1}$ ). From the estimated linear system we get the coordinates of this point, namely:

$$
a_{1}=0.56208 ; V_{1}=0.08469
$$

Notice that $a_{1}<a_{1}^{R}=0.62325$.

If the shock is permanent, the economy settles in the new steady state $E_{1}$, which will be characterized by a higher cross sectional mean of the equity ratio and a smaller variance.

Therefore also the equilibrium external finance premium will be lower:

$$
f_{1} \equiv \frac{\beta \alpha}{a_{1}}\left(1+\frac{V_{1}}{a_{1}^{2}}\right)=0.000081887
$$

curve at a point (not shown in the figure) which is much closer to the origin than the new steady state. Therefore, in the figure, the AA curve seems to have simply shifted up.

${ }^{17}$ This is due to the fact that the new (thick) VV curve, whose intercept is higher than the intercept of the old (thin) VV curve but which is also flatter, intersects the old VV curve at a point (not shown in the figure) which is much closer to the origin than the new steady state. Therefore, in the figure, the VV curve seems to have simply shifted down. 


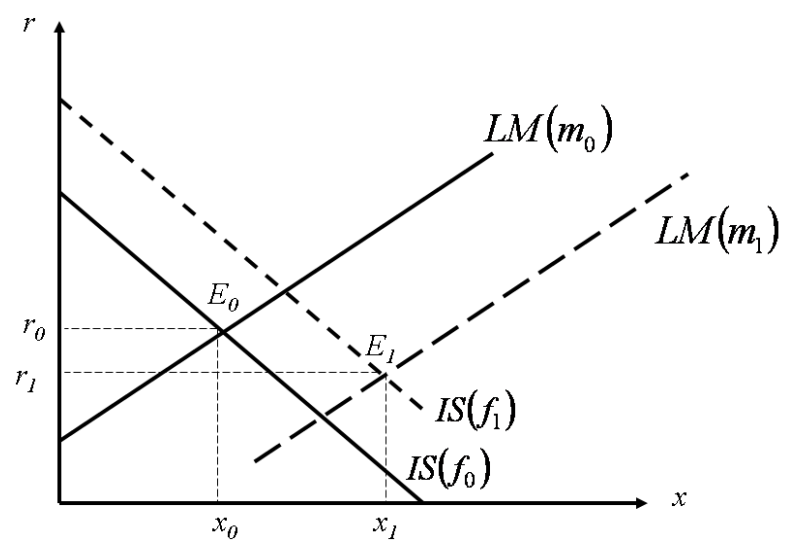

Figure 8.1: The effects of a monetary expansion

The real interest rate and the output gap can be computed from the reduced form (5.5)(5.6) using the value for $f_{1}$ above. They are:

$$
\begin{aligned}
& x_{1}=0.96464 \\
& r_{1}=0.0022744
\end{aligned}
$$

It is clear that the monetary expansion boosts the output gap while the interest rate goes down (albeit marginally).

In figure (8.1) we depict the shift of the IS and LM curves following the monetary expansion.

The LM curve shifts down because of the increase in money supply from $m_{0}$ to $m_{1}$. Keeping distributional effects out of the picture for the moment, the impact effect of the monetary expansion is a reduction of the interest rate which boosts investment and makes the output gap increase. This is the end of the story in the textbook IS-LM model but not in the present framework. In fact, the reduction of the interest rate provides a boost to the equity ratio for each and every firm (it is indeed an aggregate shock), the cross sectional mean of the equity ratio therefore goes up pushing down the external finance premium. There is an effect also on the dispersion of the 
individual equity ratios around the cross sectional mean: The variance goes down pushing down even further the external finance premium. Therefore, due to the distributional effects of the monetary shock which bring about a decrease of the external finance premium, the IS curve shifts up. The effect on the output gap is clearly expansionary. The distributional effect which impinges upon the external finance premium is the source of financial amplification. The effect on the interest rate is in principle uncertain. From our simulations, however, it turns out that also the interest rate goes down. The new long run (i.e. in the new steady state) macroeconomic equilibrium is $E_{1}$.

It is interesting to note that a monetary expansion, in our setting, brings about a shift not only of the LM curve (down) but also of the IS curve (up). This result is reminiscent of a similar outcome in Bernanke and Blinder's CC-LM model (Bernanke and Blinder, 1988): a monetary shock makes the LM curve shift down and the CC curve shift up. There is therefore an amplification of the shock - due to increased credit availability - on output, while the effect on the interest rate is somehow mitigated. In our setting the amplification is due to the reduction of marginal bankruptcy costs captured by the external finance premium.

\section{Wrap up: From micro to macro and return}

In this paper we have presented a methodology to resume macroeconomic thinking in a setting characterized by true and persistent heterogeneity of financial conditions. For each firm financial robustness is captured by the ratio of the equity base (or net worth) to the capital stock. Let's recapitualte the modelling strategy.

Step 1. First of all we have derived a microeconomic behavioural rule for investment activity (section 2). The individual investment ratio turns out to be a non-linear function of the individual equity ratio (which determines the individual external finance premium) given the real wage and the real interest rate, which are uniform across firms.

Step 2. Second, we have applied a stochastic aggregation procedure (the "modified" representative agent) to the individual investment ratio in order to derive the average investment ratio (section 3 ). The average investment ratio is decreasing with the external finance premium, which in turn depends non linearly upon the mean and the variance of the distribution of the equity 
ratio. The distribution of the equity ratio is changing over time and affects investment accordingly.

Step 3. The third step consists in framing the analysis in a general equilibrium context. First of all, we model households' behaviour (section 4). We keep things as simple and as close to the usual conceptual framework as possible. The representative household chooses the optimal consumption plan and desired money balances maximizing utility over an infinite horizon subject to a sequence of budget constraints which incorporate money and bonds. Consumption expenditure and money demand depend on the output gap and the interest rate.

In equilibrium on the goods market, the consumption of the representative agent, together with average investment, yields a relationship between the interest rate and the output gap reminiscent of the IS curve. The external finance premium (and therefore the moments of the distribution of the equity ratio) is a shifter of the IS curve.

In equilibrium on the money market, the demand for money of the representative agent, together with the (exogenous) money supply yields a relationship between the interest rate, the output gap and real money balances reminiscent of the LM curve.

In the end we obtain a simple optimizing IS-LM model, which can be solved for the equilibrium values of the interest rate and the output gap (section 5). In equilibrium $r_{t}$ and $x_{t}$ turn out to be functions of the moments of the distribution of the equity ratio $a_{t-1}$ and $V_{t-1}$.

Steps one, two and three are the milestones of a route from the micro to the macro level of analysis. The difference between the traditional microfoundations based on the representative agent and the new ones is the explicit consideration of the moments of the distribution of the equity ratio. ${ }^{18} \mathrm{By}$ focusing on moments we resume macroeconomic thinking in its purest form, i.e. at a general, non microeconomic, level, in a setting with heterogeneous agents.

Step 4. Up until step 3, we have treated the moments of the distribution as pre-determined variables $\left(a_{t-1}\right.$ and $\left.V_{t-1}\right)$. In order to endogenize

\footnotetext{
${ }^{18}$ In our simple case, since we cut short the aggregation procedure and consider only the first and second moments, the only difference between old and new microfoundations is the variance of the distribution. In fact the first moment, i.e. the mean of the equity ratio, would be present also in the traditional microfoundations. The equity ratio of the representative agent coincides with the mean of the distribution of the equity ratio when the variance is zero.
} 


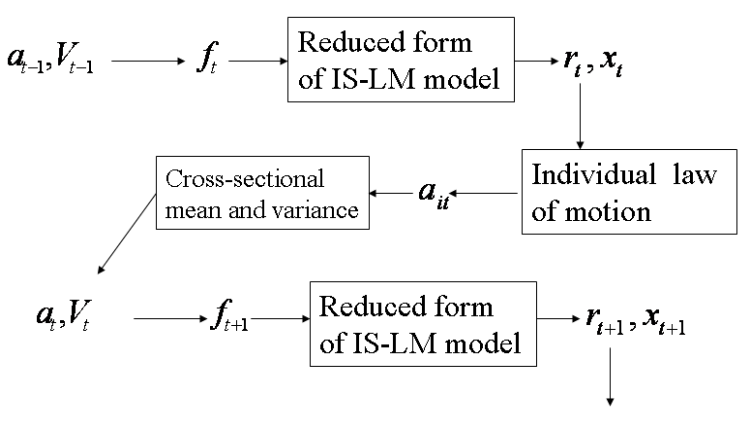

Figure 9.1: The recursive structure of the model

the dynamics of the moments, we have to go back to the micro level. We define the law of motion of the individual equity ratio $a_{i t}$ which is a function, among other things, of the interest rate. We plug the equilibrium value of the interest rate $r_{t}$ derived in step 3 into the individual law of motion. Since in equilibrium the interest rate is a function of the moments of the distribution, the current individual equity ratio turns out to be a function of the lagged cross-sectional mean and variance of the equity ratio.

Step 4 consists in running computer simulations to determine the evolution over time of the individual equity ratios (section 6). The time series of the cross sectional moments (mean $a_{t}$ and variance $V_{t}$ ) are computed directly from the empirical distribution obtained from simulated data. They will determine the new external finance premium $f_{t+1}$ and - through the reduced form of the IS-LM model - the new interest rate $r_{t+1}$ which in turn will impact upon $a_{i t+1}$ and so on, as shown in figure 9.1.

From the time series generated in this way we can compute the average long run cross sectional mean: $\hat{a}=\sum_{t=t_{0}}^{T} a_{t}$ and $\hat{V}=\sum_{t=t_{0}}^{T} V_{t}$. These are represented by the horizontal lines in the upper panels of figure 7.2. ${ }^{19}$ We can also

\footnotetext{
${ }^{19}$ The time span considered (i.e. $\left[t_{0}, T\right]$ ) excludes the transient $\left[0, t_{0}\right]$.
} 
compute the average long run interest rate and output gap: $\hat{r}=\sum_{t=t_{0}}^{T} r_{t}$ and $\hat{x}=\sum_{t=t_{0}}^{T} x_{t}$. These are represented by the horizontal lines in the lower panels of figure 7.2.

Step 5. The fifth step consists in estimating a linear system of first order difference equations in $a_{t}, V_{t}$ (see $(7.1)(7.2)$ ) by means of simple regression techniques applied to the time series of the cross sectional moments (section 7.1). Once we get numerical values for the parameters we can study this system by standard analytical techniques. It turns that the steady state is stable. The steady state of this system $\left(a_{0}, V_{0}\right)$ therefore are the numerical values of the first and second moments of the "long run" distribution of the equity ratio. Notice that $a_{0} \approx \hat{a}$ and $V_{0} \approx \hat{V}$. Moreover we can easily determine the long run external finance premium $f_{0}$.

Step 6. The sixth step consists in plugging the long run external finance premium into the equilibrium values of the macroeconomic endogenous variables. Therefore we determine the long run equilibrium values of the output gap and the interest rate $r_{0}$ and $x_{0}$ (section 7.2). Notice that $r_{0}$ is close to $\hat{r}$ and $x_{0}$ is close to $\hat{x}$ (even if the approximation is not as good as in the case of the moments of the distribution).

The combined exploitation of the linear dynamical system obtained from the simulation and of the optimizing IS-LM framework allows to cope with heterogeneity in the simplest way at a purely macroeconomic level. We have assessed the impact of a monetary expansion in our context, showing that the financial amplification effect is captured diagrammatically by shifts of the IS curve due to changes in the moments of the distribution of financial conditions.

The benchmark model lends itself to a wide range of possible extensions, such as a different monetary policy setting in a flexprice environment, the explicit consideration of income and wealth inequality among households, the role of fiscal policy and many others. We find the results reached so far, however, encouraging.

\section{A The probability of bankruptcy}

The true probability of bankruptcy can be determined as follows.

Assuming that there are no dividends, the level of net worth in real terms 
for the i-th firm in t is $A_{i t}=A_{i t-1}+\pi_{i t}$ where $\pi_{i t}=u_{i} Y_{i t}-w N_{i}-r K_{i}-\frac{1}{2} \frac{I_{i}^{2}}{\bar{K}}$

represents the profit level. We define total cost as $T C_{i}=w N_{i}+r K_{i}+\frac{1}{2} \frac{I_{i}^{2}}{\bar{K}}$. Hence $A_{i t}=A_{i t-1}+u_{i} Y_{i t}-T C_{i}$.

A firm goes bankrupt if $A_{i t}<0$, i.e. if:

$$
u_{i}<A C_{i}-\frac{A_{i t-1}}{Y_{i t}} \equiv \bar{u}_{i}
$$

where $A C_{i}=T C_{i} / Y_{i t}$ is average cost. In words: the firm goes bankrupt if the realization of the random shock is smaller than a threshold $\bar{u}_{i}$ which in turn depends on equity, output, and the average cost. By assumption, the shock is a uniformly distributed random variable $u_{i}$ with support $(0,2)$, so that the probability of bankruptcy is:

$$
\operatorname{Pr}\left(u_{i}<\bar{u}_{i}\right)=\frac{\bar{u}_{i}}{2}=\frac{1}{2}\left(A C_{i}-\frac{A_{i t-1}}{Y_{i t}}\right)
$$

Let's assume, as in the text of the paper, that the cost of bankruptcy is $C B_{i}=$ $\beta K_{i}$. The objective function of the firm $V_{i}$ is the difference between expected profit $E\left(\pi_{i t}\right)$ and bankruptcy cost in case bankruptcy occurs $C B_{i} \operatorname{Pr}\left(u_{i}<\bar{u}_{i}\right)$ :

$$
V_{i}=E\left(\pi_{i t}\right)-C B_{i} \operatorname{Pr}\left(u_{i}<\bar{u}_{i}\right)=Y_{i t}-T C_{i}-\beta^{\prime} Y_{i t}\left(A C_{i}-\frac{A_{i t-1}}{Y_{i t}}\right)
$$

with $\beta^{\prime}=\beta / 2 \nu$. Rearranging one gets:

$$
V_{i}=E\left(\pi_{i t}\right)-C B_{i} \operatorname{Pr}\left(u_{i}<\bar{u}_{i}\right)=Y_{i t}-\left(1+\beta^{\prime}\right) T C_{i}+\beta^{\prime} A_{i t-1}
$$

The present formalization of the probability of bankruptcy makes clear that taking into account the expected bankruptcy cost in the objective function is tantamount to incurring an extra cost equal to $\beta^{\prime} T C_{i}$ and gaining an extrarevenue equal to $\beta^{\prime} A_{i t-1}$.

The formalization, however, has a clear disadvantage in terms of tractability. In fact, plugging $Y_{i t}=\nu K_{i t}$ and $N_{i t}=\frac{\nu}{\lambda} K_{i t}$ into (A.1) and rearranging, 
the probability of bankruptcy turns out to be:

$$
\operatorname{Pr}\left(u_{i}<\bar{u}_{i}\right)=\frac{\bar{u}_{i}}{2}=\frac{1}{2}\left\{\frac{w}{\lambda}+\frac{r}{\nu}+\frac{1}{2} \frac{\left(K_{i t}-K_{i t-1}\right)^{2}}{\nu \bar{K} K_{i}}-\frac{a_{t i t-1}}{\nu K_{i t}} K_{i t-1}\right\}
$$

The probability of bankruptcy is decreasing with the equity ratio but it depends on a large number of parameters and endogenous variables.

Moreover, maximizing (A.2) with respect to $K_{i t}$ yields:

$$
\tau_{i t}=\frac{\nu}{2+(\beta / \nu)}-w \frac{\nu}{\lambda}-r
$$

The interior solution to the maximization of $V_{i}$ therefore is smaller than the first best $\hat{\tau}=\nu-w \frac{\nu}{\lambda}-r$ but is uniform across firms and independent of net worth. Therefore we would miss an important part of the financial fragility strory we want to tell. In order to keep net worth into the interior solution we can experiment with different bankruptcy cost functions, such as $C B_{i}=\beta K_{i}^{2}$. In this case however, the interior solution becomes rapidly very messy. With an acceptable loss of generality we adopt the approximation of the text.

\section{B Household's optimization}

The problem of the representative household is

$$
\begin{array}{cc}
\max _{c_{t}, m_{t}, b_{t}} U_{t}=\sum_{s=0}^{\infty}\left(\frac{1}{1+\rho}\right)^{s}\left(c_{t+s}\right)^{\delta}\left(m_{t+s}\right)^{1-\delta} \\
\text { s.t. } \quad c_{t}+m_{t}+b_{t}=w x_{t}+\sigma\left(1-x_{t}\right)+m_{t-1}+\left(1+r_{t}\right) b_{t-1}
\end{array}
$$

From which we obtain the following Lagrangian:

$$
\begin{aligned}
\mathcal{L}= & \sum_{s=0}^{\infty}\left(\frac{1}{1+\rho}\right)^{s}\left(c_{t+s}\right)^{\delta}\left(m_{t+s}\right)^{1-\delta}+ \\
& +\left(\frac{1}{1+\rho}\right)^{s} \lambda_{t+s}\left[w x_{t+s}+\sigma\left(1-x_{t+s}\right)+m_{t-1+s}+\right. \\
& \left.\left(1+r_{t+s}\right) b_{t-1+s}-c_{t+s}-m_{t+s}-b_{t+s}\right]
\end{aligned}
$$


The FOCs are:

$$
\begin{gathered}
\frac{\partial L}{\partial c_{t}}=\delta\left(c_{t}\right)^{\delta-1}\left(m_{t}\right)^{1-\delta}=\lambda_{t} \\
\frac{\partial L}{\partial m_{t}}=(1-\delta)\left(c_{t}\right)^{\delta}\left(m_{t}\right)^{-\delta}-\lambda_{t}+\left(\frac{1}{1+\rho}\right) \lambda_{t+1}=0 \\
\frac{\partial L}{\partial b_{t}}=-\lambda_{t}+\left(\frac{1}{1+\rho}\right) \lambda_{t+1}\left(1+r_{t}\right)=0
\end{gathered}
$$

Solving (B.2) (B.3) (B.4) for $c_{t}, m_{t}$ we obtain the following relation between optimal consumption and money demand:

$$
m_{t}=\frac{1-\delta}{\delta} \frac{1+r_{t}}{r_{t}} c_{t}
$$

assuming, for the sake of simplicity, $\delta=1 / 2$ we get equation (4.3) in the text.

\section{Law of motion of the equity ratio}

Assuming that there are no dividends, the level of net worth in real terms for the i-th firm in $t$ is defined as $A_{i t}=A_{i t-1}+\pi_{i t}$. Recalling (2.1) we get:

$$
A_{i t}=A_{i t-1}+u_{i t} Y_{i t}-w N_{i t}-r_{t} K_{i t}-\frac{1}{2} \frac{I_{i t}^{2}}{\overline{K_{t-1}}} ; \quad i=1,2, \ldots, z
$$

Dividing by $K_{i t}$ we obtain the law of motion of the equity ratio:

$$
a_{i t}=a_{i t-1} \frac{K_{i t-1}}{K_{i t}}+u_{i t} \nu-w \frac{\nu}{\lambda}-r_{t}-\frac{1}{2} \frac{I_{i t}^{2}}{K_{i t} \bar{K}_{t-1}}
$$

Recall now that $g_{i t}=\frac{I_{i t}}{K_{i t-1}}=\frac{\tau_{i t}}{s_{i t-1}}$ where $s_{i t-1}=\frac{K_{i t-1}}{\bar{K}_{t-1}}$. Therefore $\frac{K_{i t-1}}{K_{i t}}=\frac{1}{1+g_{i t}}=\frac{s_{i t-1}}{s_{i t-1}+\tau_{i t}}$. Moreover $\frac{I_{i t}^{2}}{K_{i t} \bar{K}_{t-1}}=\frac{I_{i t}^{2}}{\bar{K}_{t-1}^{2}} \frac{\bar{K}_{t-1}}{K_{i t-1}} \frac{K_{i t-1}}{K_{i t}}=$ 
$\frac{\tau_{i t}^{2}}{s_{i t-1}+\tau_{i t}}$. Plugging these expressions into (??) we obtain:

$$
a_{i t}=a_{i t-1}\left(\frac{s_{i t-1}}{s_{i t-1}+\tau_{i t}}\right)+u_{i} \nu-w \frac{\nu}{\lambda}-r_{t}-\frac{1}{2} \frac{\tau_{i t}^{2}}{s_{i t-1}+\tau_{i t}}
$$

which is $(6.1)$. 


\section{References}

[1] Agliari, A., Delli Gatti, D., Gallegati, M. and Gardini, L. (2000), "Global Dynamics in a Non-linear Model of the Equity Ratio", Journal of Chaos, Solitons and Fractals.

[2] Bernanke, B. and Blinder, M. (1988), "Is it Money or Credit or Both or Neither", American Economic Review, 78.

[3] Bernanke, B. and Gertler, M. (1989), "Agency Costs, Net Worth and Business Fluctuations", American Economic Review, 79, pp. 14-31.

[4] Bernanke, B. and Gertler, M. (1990), "Financial Fragility and Economic Performance", Quarterly Journal of Economics, 105, pp. 87-114.

[5] Bernanke, B., Gertler, M. and Gilchrist, S. (1999), "The Financial Accelerator in Quantitative Business Cycle Framework", in Taylor, J. e Woodford, M. (eds), Handbook of Macroeconomics, vol 1C, North Holland, Amsterdam.

[6] Gallegati, M., Palestrini, A., Delli Gatti, D. and Scalas, E. (2006) "Aggregation of Heterogeneous Interacting Agents: The Variant Representative Agent" Journal of Economic Interaction and Coordination, vol. 1 pp. 5-19.

[7] Greenwald, B, Stiglitz, J. and Weiss, A. (1984) "Informational Imperfections in the Capital Market and Macroeconomic Fluctuations" (with J. Stiglitz and A. Weiss), American Economic Review.

[8] Greenwald, B. and Stiglitz, J.(1988), "Imperfect Information, Finance Constraints and Business Fluctuations", in Kohn, M. and Tsiang, S. (eds.)

[9] Greenwald, B. and Stiglitz, J.(1990), "Macroeconomic Models with Equity and Credit Rationing", in Hubbard, R.G. (ed.) Asymmetric Information, Corporate Finance and Investment, Chicago: University of Chicago Press.

[10] Greenwald, B. and Stiglitz, J. (1993), "Financial Market Imperfections and Business Cycles", Quarterly Journal Of Economics, vol. 108, pp. 77-114. 
[11] Greenwald, B. and Stiglitz, J.(2003), "Towards a New Paradigm in Monetary Economics" Cambridge University Press.

[12] Kiyotaki, N. and Moore, J. (1997), "Credit Cycles", Journal of Political Economy, 105, pp.211-248.

[13] Kiyotaki, N. and Moore, J. (2002), "Balance-Sheet Contagion," American Economic Review, vol. 92(2), pp. 46-50.

[14] Krusell, P. and Smith, A. (1998), "Income and Wealth Heterogeneity in the Macroeconomy" Journal of Political Economy, vol. 106, no. 5 pp. 867-896.

[15] Myers, S. and Majluf, N. S. (1984) "Corporate Financing and Investment Decisions when Firms have Information that Investors Do Not Have", Journal of Financial Economics, vol. 13, no. 2, pp. 187-221.

[16] Tesfatsion, L. (2006) "Handbook of Computational Economics: Volume 2, Agent-Based Computational Economics", Handbooks in Economics Series, Elsevier, North-Holland Imprint, Amsterdam, The Netherlands. 